\title{
Şanlıurfa İlinde Siyah Alaca Irkı Sığırların Yetiştirici Şartlarında Bazı Adaptasyon Özellikleri
}

\author{
Ali KAYGISIZ ${ }^{\mathscr{8}} \quad$ İsa YILMAZ ${ }^{2} \quad$ Selçuk KOŞUM ${ }^{3}$ \\ ${ }^{1}$ Kahramanmaraş Sütçü İmam Üniv., Ziraat Fak. Zootekni Böl., Kahramanmaraş \\ ${ }^{2}$ Iğdır Üniversitesi, Ziraat Fak., Zootekni Böl., Iğdır \\ ${ }^{3}$ Kahramanmaraş Sütçü İmam Üniv., Fen Bilimleri Enst., Zootekni Ana Bilim Dalı, Kahramanmaraş \\ $\bowtie$ : alikaygisiz@ksu.edu.tr
}

Geliş (Received): 01.09.2016

Kabul (Accepted): 01.10.2016

\begin{abstract}
ÖZET: Bu çalışmanın amacı Şanlıurfa ilinde yetiştirici şartlarındaki Siyah Alaca sı̆̆ırların adaptasyon özelliklerini incelemektir. Araştırmanın materyalini 2013-2014 yılları arasında Şanlıurfa ilinde büyükbaş hayvan hayat sigortası yaptırılan Siyah Alaca ırkı sığırlara ait veriler oluşturmuştur. İl genelinde inek ölüm oranı \% 7.5, mecburi kesim oranı \% 3.8, yavru atma oranı \% 6.58 ve buzağılarda 7. güne kadar ölüm oranı \% 7.95 (yaşama gücü \% 92.05) olarak belirlenmiştir. Araştırma bulgularına göre Siyah Alaca ırkın bölgede yetiştiriciler tarafindan benimsendiği ancak bakım-besleme ve barındırılması konusunda önemli problemlerin olduğu sonucuna varılmıştır.
\end{abstract}

Anahtar Kelimeler: Siyah Alaca, inek ölüm oranı, zorunlu kesim oranı, yavru atma oranı, yaşama gücü oranı.

\section{Some Adaptation Traits of Holstein Cattle Raised under Breeders Conditions in Sanlıurfa Province}

ABSTRACT: The objective of this study was to determine some adaptation traits of Holstein cattle raised under breeder conditions in Sanliurfa Province. Data were obtained from Holstein cattle which had life insurance between 2013 and 2014 in the Province. Throughout the city, the means for the adaptation characteristics were found as 7.5 $\%, 3.8 \%, 6.58 \%$, and $7.95 \%$, (survival ratio $92.05 \%$ ) for the cattle mortality ratio, compulsory slaughtion, abortion and calves mortalities up to seven days of ages, respectively. The study indicated that Holstein cattle was adopted by breeders in the region, however there were important problems for their care-feeding and sheltering.

Key Words: Holstein, cattle mortality rate, compulsory slaughtion rate, abortion rate, survival rate

\section{GİRIŞ}

Holstein-Friesian (Siyah-Alaca) sığır ırkı, Dünyada geniş yayılma alanı olan ve süt verimi en yüksek sığır 1rkıdır. Siyah Alaca iyi bakım, besleme ve serin iklim koşulları altında geliştirilmiş bir ırktır. $\mathrm{Bu}$ nedenle verim yeteneklerini en iyi, bol yem üretilebilen serin iklimli ovalık bölgelerde gösterirler. Sıcak iklime sahip bölgelerde, kötü bakım ve besleme koşulları altında verim seviyesi düşmektedir. Yüksek süt verme yeteneğinin yanında et veriminin de iyi olması nedeniyle bu 1 rk dünyanın birçok ülkesine götürülmüştür ve bu ülkelerdeki sayıları diğer ırklar aleyhine sürekli artış göstermektedir (Url, 2016a).

Siyah Alaca 1rkı Türkiye'ye 1958 yılında Amerika Birleşik Devletleri'nden Bursa Karacabey Harası'na getirilen inek ve boğalar ile yetiştirilmeye başlanmıştır. İlerleyen yıllarda Almanya, İngiltere, İsrail, Danimarka ve tekrar Amerika Birleşik Devletleri'nden devlet üretme işletmelerine ve bazı özel işletmelerin isteği üzerine Siyah Alaca inek ve boğalar ithal edilmiştir (Erdoğdu Tatar, 2015). Başlangıçta Marmara, Ege ve Akdeniz kıyı şeridinde yetiştirilen bu 1rk, kısa zamanda İç ve Doğu Anadolu bölgelerine kadar ulaşmıştır (Akbulut ve ark., 1992).

2015 TUİK verilerine göre Türkiye'deki 14.244.673 baş sığır varlığının 6.385.343 (\% 45.6) başını kültür ırkları oluşturmaktadır. Kültür ırkları içerisinde de en fazla paya sahip olan ırk ise Siyah Alaca ırkıdır. (Url, 2016c)
Buzağı ve/veya inek yaşama gücü ithal edilen ırklar için en önemli adaptasyon kriterlerinden biridir. Bu sebeple süt sığırcılığı işletmelerinde, yılda bir canlı buzağı elde edilmeli ve buzağı kayıplarının mümkün olduğunca azaltılmasına yönelik çalışmalar yapılmalıdır. Değişik çevre koşullarına uyum sağlayan 1rklarda yaşama gücünün yüksek bulunmasına karşın, uyum sağlayamayanlarda yaşama gücü düşük bulunmaktadır (Karakaş, 2002)

Bugüne kadar kültür ırkı sığırlarla ilgili adaptasyon çalışmalarının çoğu kamuya ait işletmelerde yapılmıştır. Irkın yetiştirici şartlarındaki verim düzeyi üzerine kapsamlı bir araştırma yapılmamıştır. Daha önce yapılmış çalışmalardan farklı olarak bu çalışma hem yetiştirici şartlarında yapılmış, hem de sigortadan hasar alma düzeyleri bakımından adaptasyon yeteneği de ele alınmıştır.

$\mathrm{Bu}$ çalışmada Siyah Alaca sığırlarının Şanlıurfa yetiştirici şartlarındaki adaptasyon özelliklerinin ortaya konması amaçlanmıştır.

\section{MATERYAL ve METOD}

Materyal

Araştırmanın materyalini 2013-2014 yıllarında Şanlıurfa ilinde yaptırılan Siyah Alaca ırk sığır büyükbaş hayvan hayat sigortası verileri oluşturmuştur. Sigorta bilgileri TARSIM (Tarım Sigortaları Havuzu)'den temin edilmiştir. Sigortalanan hayvanların 
1rk bilgileri E-Devlet sisteminden alınmıştır (Url, 2016d).

\section{Metod}

Çalışmada üzerinde durulan adaptasyon özellikleri aşağıda verilmiştir.

İnek ölüm oranı: İneklerden sigortalanma tarihinden itibaren 1 yıl içinde ölenlerin oranını,

Zorunlu kesim oranı: İneklerden sigortalanma tarihinden itibaren 1 y1l içinde zorunlu olarak kesime sevk edilenlerin oranını,

Yavru atma oranı: İneklerden sigortalanma tarihinden itibaren 1 yıl içinde yavru atanların oranını,

Yaşama gücü: Doğan buzağılardan ilk 7 gün içerisinde canlı kalanların oranını ifade etmektedir.

Sigorta birim bedelleri, prim bedeli ve sigorta tazminat bedelleri TARSIM'in her yıl yayınlamış olduğu tarife ve talimatlar doğrultusunda hesaplanmıştır (Url, 2016b).

\section{BULGULAR ve TARTIŞMA}

\section{İlçelere Göre Siyah Alaca Irkının Dağılımı}

İlçelere göre Siyah Alaca ırkının dağılımı Çizelge 1'de verilmiştir. Şanlıurfa ilinde 2013-2014 yıllarında sigortalanan büyükbaş hayvanların \% 74'ü Siyah Alaca ve \% 26'sı diğer rrklardan oluşmuştur (Şekil 1). İlçelere göre dağılım incelendiğinde ise Harran, Haliliye ve Hilvan'da sigortalanan büyükbaş hayvanların tamamı Siyah Alaca ırkına ait iken Siverek (\% 49), Merkez (\% 44) ve Viranşehir (\% 42) ilçelerinde diğer ırktan sığırlar da tespit edilmiştir.

Çizelge 1. İlçelere Göre Irkların Dağılımı

\begin{tabular}{|l|c|c|r|c|r|}
\hline İlçe & Siyah Alaca & $\%$ & Diğer & $\%$ & Toplam \\
\hline Akçakale & 3154 & 0.98 & 69 & 0.02 & 3223 \\
\hline Birecik & 557 & 0.99 & 6 & 0.01 & 563 \\
\hline Bozova & 3411 & 0.95 & 163 & 0.05 & 3574 \\
\hline Halfeti & 314 & 0.92 & 26 & 0.08 & 340 \\
\hline Haliliye & 1087 & 1.00 & 0 & 0.00 & 1087 \\
\hline Harran & 589 & 1.00 & 1 & 0.00 & 590 \\
\hline Hilvan & 1384 & 1.00 & 3 & 0.00 & 1387 \\
\hline Merkez & 7055 & 0.56 & 5655 & 0.44 & 12710 \\
\hline Siverek & 777 & 0.51 & 733 & 0.49 & 1510 \\
\hline Suruç & 742 & 0.98 & 14 & 0.02 & 756 \\
\hline Viranşehir & 520 & 0.58 & 383 & 0.42 & 903 \\
\hline Genel & 19590 & 0.74 & 7053 & 0.26 & 26643 \\
\hline
\end{tabular}

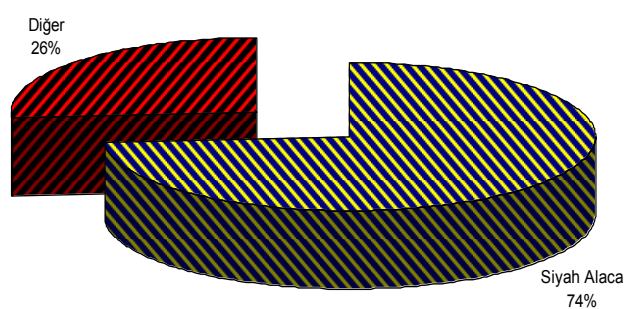

Şekil 1. İlde Siyah Alaca Irkının Dağılımı

\section{Sigorta Birim, Prim ve Tazminat Bedelleri}

Sigorta birim bedeli, prim bedelleri ve alınan hasar bilgileri Çizelge 2'de verilmiştir.

Alınan primlerin \% 89'u tazminat olarak yetiştiriciye ödenmiştir. 2013-2014 yıllarında Şanlıurfa'da Siyah Alaca ırkından toplam 19590 baş hayvan sigortalanmış, müteakip y1l içerisinde 4753 hayvan için hasar ihbarı yapılarak tazminat alınmıştır. Sigortadan tazminat alma sebepleri inek ölümü (\% 7.5), zorunlu inek kesimi (\% 3.8), yavru atma (\% 6.58) ve yavru ölümü (\% 7.98) olarak sıralanmıştır (Çizelge 3).

Çizelge 2. Birim maliyet ve prim bedelleri

\begin{tabular}{|c|c|c|c|c|}
\hline $\mathrm{N}$ & $\begin{array}{c}\text { Birim } \\
\text { Bedel }\end{array}$ & $\begin{array}{c}\text { Prim } \\
\text { Bedeli }\end{array}$ & $\begin{array}{c}\text { Hasar } \\
\text { bedeli }\end{array}$ & $\begin{array}{c}\text { Hasar: } \\
\text { Prim oranı }\end{array}$ \\
\hline 19590 & $5041 \pm 10$ & $494.3 \pm 1.5$ & $442 \pm 7.9$ & $\% 89$ \\
\hline
\end{tabular}

\section{İnek Ölüm ve Zorunlu Kesim Oranı}

Y1l içerisinde ölen veya zorunlu kesime tabii tutulan inek oranı toplamı \% 11.3, inek yaşama gücü ise \% 88.7 olarak hesaplanmıştır. Elde edilen bu değer, Işık (2006) tarafindan Antalya İli Holstein Damızlık Sığır Yetiştiricileri Birliği'ne kayıtlı Siyah Alaca sürüsü için bildirilen \% 5.0, Tüzemen ve ark. (1997) ve Akbulut ve ark. (1993) tarafından Erzurum A.Ü. Ziraat işletmesinde yetiştirilen Siyah Alacalarda 0-12 aylık dönem için bildirilen \% 4.54 ve \% 7.8, Özçakır ve Bakır (2003) tarafından Tahirova TíM'de yetiştirilen Siyah Alacalarda 0-12. aylık dönem için bildirilen \% 3.78, Ertuğrul ve ark. (1998) tarafından Karacabey TíM'de yetiştirilen Siyah Alacalarda 0-12. aylık dönem için bildirilen \% 2.5 değeri, Yaylak (2003) tarafindan İzmir İli Holstein Damızlık Sı̆̆ır Yetiştiricileri Birliği'ne kayıtlı (Ödemiş) Siyah Alaca sürüsü için bildirilen \% 2.2, ve Moussavi (2008) tarafından İran'da yetiştirilen Holstein inekler için bildirilen \% 0.618 değerlerinden yüksek bulunmuştur. Diğer yandan bu araştırmada ölen veya zorunlu kesime sevk edilen inek oranı bakımından elde edilen değer Amerika'da Smith ve ark. (2000) tarafindan Holsteinler için bildirilen \% 16.8-\% 18.2, Türkiye'de ise Bülbüller (2000) tarafindan Van iline ithal edilen Siyah Alaca rrkları için bildirilen \% 21.7 değerlerinden ise daha düşük bulunmuştur.

Yaşama gücü olarak hesaplanan \% 88.7 değeri ise Koçak ve ark. (2007) tarafindan Ceylanpınar TİM'de yetiştirilen Siyah Alaca sığırların 12.ay yaşama gücü için bildirilen \% 92 değeri, Sehar ve Özbeyaz (2005) tarafindan Koçaş TíM'de yetiştirilen Siyah Alaca sığırların 180. gün yaşama gücü için bildirilen \% 92.1 değeri, Koçak ve ark. (2008)'nın Lalahan MHAE'nde yetiştirilen Siyah Alaca sığırların 180. gün yaşama gücü için bildirilen \% 93 değeri ile benzerdir.

\section{Buzağılarda Yaşama Gücü}

Yaşama gücü ırkın bölge ve işletmeye uyumunun önemli bir göstergesi olup, diğer verimler için de iyi bir kriterdir (Tüzemen ve ark., 1997). Zira, doğan buzağıların verimli döneme geçmeden ölmeleri önemli ekonomik kayılara neden olmaktadır. 
Çizelge 3. Tazminat sebeplerinin 1rklara göre dağılımı

\begin{tabular}{|c|c|c|c|c|c|c|}
\hline Sigortalanan Hayvan & İnek Ölüm oranı & Zorunlu Kesim & Yavru Atma & Yavru Ölümü & Toplam & $\%$ \\
\hline 19590 & $\% 7.5$ & $\% 3.8$ & $\% 6.58$ & $\% 7.95$ & 4753 & 24 \\
\hline
\end{tabular}

Buzağılarda 7. gün yaşama gücü \% 92.05 (ölüm oranı \% 7.95) olarak belirlenmiştir. Bu değer Doğu Akdeniz Tarımsal Araştırma Enstitüsü'nde yetiştirilen Siyah Alacalar için bildirilen \% 96.34 (Ayaşan ve ark., 2016), Ceylanpınar ve Koçaş TİM'de 30. gün yaşama gücü için bildirilen \% 95 (Koçak ve ark., 2007) ve \% 94.4 (Sehar ve Özbeyaz, 2005) değerlerinden daha düşük bulunmuştur. Ancak bu çalışmada elde edilen yaşama gücü oranı, Bursa ili yetiştirici şartlarında tesbit edilen Siyah Alacalar için bildirilen \% 85.9 (Karakaş, 2002) değerinden ise yüksek bulunmuştur. Şanlıurfa ili şartlarında elde edilen bu sonuçlar, literatür bildirişleri ile karşılaştırıldığında doğumdan sonraki ilk bir haftalık dönemde yaşama gücü bakımından buzağılarda sorun olduğu görülmektedir.

\section{Yavru Atma Oran}

Y1l içerisinde yavru atma oranı \% 6.58 olarak tespit edilmiştir. Bu değer Tahirova TİM'de bildirilen \% 0.43 (Özçakır ve Bakır, 2003), Kahramanmaraş TİM'de bildirilen \% 0.97 (Kaygisız, 1997), Erzurum'da bildirilen \% 1.13 ve \% 5 (Tüzemen ve ark., 1997, Akbulut ve ark., 1993), Koçaş TİM'de bildirilen \% 1.9 (Sehar ve Özbeyaz, 2005), Reyhanlı TİM'de bildirilen \% 2.49 (Bakır ve Çetin, 2003) değerlerinin hepsinden yüksek bulunmuştur.

\section{SONUÇ ve ÖNERILER}

Yetiştiriciler verim düzeyi yüksek ve ekonomik değeri olan sığırlarını sigorta yaptırma eğilimindedir. Bu kapsam da il genelinde sigorta yaptırılan sığırların \% 74'ünü Siyah Alaca sığır ırkı oluşturmaktadır. Bu sonuç kültür ırkları içerisinde Siyah Alaca ırkının bölgede yetiştiriciler tarafından daha fazla benimsendiğini göstermektedir. Ancak, inek ve buzağı yaşama gücü değerleri gerek ülke ve gerekse bölgede daha önce yapılan çalışmalarda bildirilen değerlerin hala altındadır. $\mathrm{Bu}$ bulguların 1şığı altında, inek ve buzağılarda yaşama gücü bakımından sürü idaresinin daha da iyileştirilmesi gerektiği söylenebilir. Sürüdeki yaşama gücü düşüklüğüne neden olan problemlerin giderilmesi ile verimlilik artırılabilecektir.

Diğer taraftan hasar/prim oranının \% 89 olarak gerçekleşmesi il genelinde irkın bakım-besleme ve barındırılması konusunda problemlerin varlığına işaret etmektedir.

\section{KAYNAKLAR}

Akbulut Ö, Tüzemen N, Yanar M 1992. Erzurum Şartlarında Siyah Alaca Sı ğırların Verimi : 1. Döl ve Süt Verim Özellikleri. DOĞA, Türk Vet. ve Hayvanc1lık Dergisi, 16: 523-533.

Akbulut Ö, Tüzemen N, Aydın R 1993. Erzurum Şartlarında Siyah Alaca Sığırların Verimi. 2 Doğum
Ağırlığı, Büyüme ve Yaşama Gücü Özellikleri. DOĞA, Türk Vet. ve Hayvancılık Dergisi, 17 : (3): 193-200

Ayaşan T, Hızlı H, Asarkaya A, Coşkun MA 2016. Growth Performance and Survival Rate Traits in Holstein Calves.Turkish Journal of Agricultural and Natural Science,3(3), 223-228.

Bakır G, Çetin M 2003. Reyhanlı Tarım İşletmesinde Yetiştirilen Siyah Alaca Sığırlarda Döl ve Süt Verim Özellikleri. Turkish Journal of Veterinary and Animal Sciences, 27(1):173-180

Bülbüller Ş 2000. Van İline İthal Edilen Kültür Irk1 Damızlık Sığırların Süt ve Döl verim Özellikleri. Yüzüncü Y1l Üniversitesi, Fen Bilimleri Enstitüsü, Zootekni Ana Bilim Dalı, Yüksek Lisans Tezi, Van.

Ertuğrul O, Ünal N, Azeroğlu F, Kaya O 1998. Açıta ve Bireysel Kulübelerde Barındırılan Buzağılarda Büyüme ve Yaşama Gücü. TÜBİTAK VHAG Proje No. 1174, 1-57.

Erdoğdu Tatar G 2015. Irklarımızı Tanıyalım HolsteinSiyah Alaca. Türkiye Damızlık Sığır Yetiştirici Merkez Birliği, Damızlık Sığır Yetiştiricileri Dergisi Mart-Nisan Sayıs1: 42-43

Işık UE 2006. Antalya'da Siyah Alaca Irkı İneklerin Damızlıkta Kalma Süresi ve Sürüden Çıkma Nedenleri Üzerine Bir Araştırma. Akdeniz Üniversitesi, Fen Bilimleri Enstitüsü, Zootekni Ana Bilim Dalı, Yüksek Lisans Tezi.

Karakaş E, 2002. Bursa-Yenişehir İlçesinde Yetiştirilen Holştayn Buzağıların Doğum Ağırlığı Sütten Kesim Yaşı, Süt Tüketimleri ve Yaşama Güçleri. Uludağ Üniversitesi Veteriner Fakültesi Dergisi, 21(1-23):77-81

Kaygısız A 1997. Siyah Alaca Sığırların Kahramanmaraş Tarım İşletme Şartlarındaki Verim Özellikleri. Tarım Bilimleri Dergisi, 3(2):9-22

Koçak S, Tekerli M, Özbeyaz C, Demirhan İ 2008. Lalahan Merkez Hayvancılık Araştırma Enstitüsün'de yetiştirilen Holştayn, Esmer ve Simental Sığırlarda Bazı Verim Özellikleri. Lalahan Hayvancılık Araştırma Enstitüsü Dergisi., 48(2):5157

Koçak S, Tekerli M, Özbeyaz C, Yüceer B 2007. Holştayn Buzağılarda Genetik ve Çevresel Faktörlerin Doğum Ağırlığı ve Yaşama Gücü Üzerine Etkileri. Turkish Journal of Veterinary and Animal Sciences, 31(4):241-246.

Moussavi AH 2008. Days in Milk at Culling in Holstein Dairy Cows. Journal of Animal and Veterinary Advances, 7(1) : 89-93.

Özçakır A, Bakır G 2003. Tahirova Tarım İşletmesinde Yetiştirilen Siyah Alaca Sığırların Döl ve Süt Verim Özellikleri 2. Döl Verim Özellikleri. Atatürk Üniversitesi Ziraat Fakültesi Dergisi, 34(3):223-228. 
Sehar Ö, Özbeyaz C 2005. Orta Anadoludaki Bir İşletmede Holştayn Irkı Sığırlarda Bazı Verim Özellikleri. Lalahan Hayvancılık Araştırma Enstitüsü Dergisi, 45(1):9-16.

Smith JM, Ely LO, Chapa AM 2000. Effect of region, Herd Size and Milk Production on Reason Cows leave the Herd. J Dairy Sci., 83:2980-2987.

Tüzemen N, Akbulut Ö, Özhan M 1997. Esmer ve Siyah Alaca sığırların Erzurum Koşullarında Büyüme ve Gelişme Özelliklerinin Karşılaştırılması. TÜBİTAK VHAG Proje No. 876, 1997: 1-64.

Url, 2016a. Breeds of Livestock - Holstein Cattle. http://www.ansi.okstate.edu/breeds/cattle/holstein. (2016, Eylül)
Url, 2016b. Devlet Destekli Büyükbaş Hayvan Hayat Sigortas1 Tarife ve Talimatlar. http://www.tarsim.gov.tr/trsmWeb/dokumanGoster. doc?_id_=32454

Url, 2016c. Türkiye İstatistik Kurumu, Hayvansal Üretim İstatistikleri, http://tuikapp.tuik.gov.tr/ hayvancilikapp/ hayvancilik.zul, (2016, Eylül).

Url, 2016d. Küpe İle Büyükbaş Hayvan Sorgulama. https://www.turkiye.gov.tr/gtvh-kupe-ile-buyukbashayvan-sorgulama

Yaylak E 2003. Siyah Alaca İneklerde Sürüden Çıkarılma Nedenleri, Sürü Ömrü ve Damızlıkta Yararlanma Süresi. Akdeniz Üniversitesi Ziraat Fakültesi Dergisi, 16(2):179-185 